\title{
Dupuytren Kontraktürü: Parsiyel Fasiektomi Uygulanan 32 Hastanın Retrospektif Analizi
}

\author{
Sercan ÇAPKIN, Tufan KALELI
}

Bursa Uludağ Üniversitesi Tıp Fakültesi, Ortopedi ve Travmatoloji Anabilim Dalı, El Cerrahisi Bilim Dalı, Bursa.

\begin{abstract}
ÖZET
Dupuytren kontraktürü nedeniyle parsiyel fasiektomi uyguladığımız 32 hastanın demografik ve klinik özellikleri, fonksiyonel sonuçları, komplikasyon ve nüks oranları güncel literatür eşliğinde tartışıldı. Çalışmamızda; erkek/kadın oranı: 7/1, hastalığın başlangıcındaki ortalama yaş 55.4 \pm 7.1 , cerrahi esnasındaki ortalama yaş $60.4 \pm 8.1$ olarak tespit edildi. 7 hastada (\%21.875) aile öyküsü, 22 hastada (\%68.75) sigara kullanımı, 6 hastada $(\% 18,75)$ düzenli alkol kullanımı, 10 hastada $(\% 31,25)$ tip 2 diyabet, 2 hastada $(\% 6.25)$ karaciğer hastalığı, 1 hastada (\%3.125) epilepsiye bağlı uzun süre barbitürat kullanımı gibi etiyolojik faktörler mevcuttu. En sık etkilenen parmak 26 hasta (\%81.25) ile yüzük parmağı olup, 18 hastada (\%56.25) küçük parmak, 8 hastada (\%25) orta parmak, 1 hastada (\%3.125) işaret parmağı tutulumu vardı. Ameliyat öncesi, ortalama total pasif ekstansiyon kaybı (TPEK) $89.68^{\circ} \pm 30.29$, ameliyat sonrası ortalama TPEK $6.09^{\circ} \pm 6.44$ olarak bulundu. Ameliyat sonrası ortalama total ekstansiyon kazancı $\% 93.2$ olarak bulundu. Ortalama takip süresi $70 \pm 44$ ay olup, bu süre içerisinde 1 hastada (\%3.125) nüks görüldü. 2 hastada pansumanlara sekonder iyileşen cilt nekrozu, 1 hastada geçici hipoestezi olmak üzere toplam 3 hastada (\%9.375) komplikasyon meydana geldi. MKF ve PİP eklem kontraktüründe yeterli düzelme sağlaması, komplikasyon ve nüks oranlarının düşük olması nedeniyle parsiyel fasiektomi dupuytren kontraktürünün cerrahi tedavisinde etkili ve güvenilir bir yöntemdir.
\end{abstract}

Anahtar Kelimeler: Dupuytren Hastalığı. Kontraktür. Parsiyel fasiektomi.

Dupuyten's Contracture: Retrospective Analysis of 32 Patients Operated by Partial Fasciectomy

\section{ABSTRACT}

Demographic and clinical features of 32 patients diagnosed with dupuytren contracture and operated by partial fasciectomy were included in this study. Functional results, complications and recurrence rates were discussed with current literature. In our study male/female ratio was $7 / 1$, mean age at onset of disease was $55.4 \pm 7.1$, mean age at surgery was $60.4 \pm 8.1$. There were etiological factors such as a family history in 7 patients (21.875\%), smoking in 22 patients (68.75\%), regular alcohol use in 6 patients (\%18,75), type 2 diabetes in 10 patients (31.25\%), hepatic disease in 2 patients (6.25\%), long term barbiturate use for epilepsy in 1 patients (3.125\%). The most often involved finger was the ring finger in 26 patients (81.25\%), the small finger in 18 patients (56.25\%), middle finger in 8 patients (25\%) and index finger in 1 patient (3.125\%). The pre-operative mean total passive extension deficit (TPEK) was $89.68^{\circ} \pm 30.29$, the post-operative mean TPED was $6.09^{\circ} \pm 6.44$. The post-operative mean total extension gain was $93.2 \%$. The mean follow-up was $70 \pm 44$ months, 1 patient (3.125\%) had a recurrence in this period. The overall complications occured in 3 patients (9.375\%), including skin necrosis in 2 patients (treated with dressings) and temporary hypoesthesia in 1 patient. The partial faciectomy is an effective and reliable method for the surgical treatment of dupuyren contracture because of improvement enough correction in the MCF and PIP joint contracture, the low rate of complication and recurrence rates.

Key Words: Dupuytren's disease. Contracture. Partial Fasciectomy.

Geliş Tarihi: 02 Ocak 2019

Kabul Tarihi: 08 Nisan 2019

\section{Dr. Sercan ÇAPKIN}

Bursa Uludağ Üniversitesi Tıp Fakültesi,

Ortopedi ve Travmatoloji A.B.D,

El Cerrahisi Bilim Dalı,

16059, Görükle BURSA

Tel.: 05068427596

E-posta: sercancapkn@gmail.com
Dupuytren kontraktürü, parmakların ilerleyici fleksiyon deformitesine neden olan, etiyolojisi tam olarak bilinmeyen palmar fasyanın fibroproliferatif bir hastalığıdır. İlk olarak Henry Cline tarafından tanımlanan hastalık daha sonra Fransiz cerrah Baron Dupuytren tarafindan ayrıntılı bir şekilde tanımlanarak kendi ismiyle anılmaya başlanmıştır ${ }^{1,2}$. Hastalık tipik olarak kuzey Avrupa'daki yaşlı erkekleri etkiler. Erkek/kadın oranı 7/1 ile 15/1 arasında değişmekle birlikte, erkeklerde kadınlara nazaran daha erken yaşlarda başlayıp daha ciddi hastalığa neden olur ${ }^{3}$. Palmar cildin çukurlaşması ve kalınlaşması en erken belirtidir. Bununla birlikte tanı cilt veya fasyaya lokalize ağrısız sert bir 
nodülün varlığı ile konur. Nodül aylar/yıllar içerisinde korda dönüşür. Kord bir kez meydana geldiğinde zaman içerisinde kasılarak metakarpofalangeal (MKF) eklem ve proksimal interfalangeal (PIP) eklemde ilerleyici fleksiyon kontraktürüne yol açar. Sonunda çalışma ve günlük aktivitelerde işlev bozukluğuna yol açan kozmetik bir deformite ortaya çıkar. En sık yüzük ve küçük parmaklar etkilenir ${ }^{4}$. Dupuytren hastalığ1; Garrod' un eklem yastıkçıkları (\%44-54), plantar fibromatozis (Ledderhose hastalığı, \%6-31) ve penil fibromatozis (Peyronie hastalığ $1, \% 2-8$ ) gibi vücudun diğer bölümlerinde de görülebilir. Ayrıca epilepsi nedeniyle uzun süre barbitürat kullanımı, karaciğer hastalığ1, diabetes mellitus, romatoid artrit, hiperkolesterolemi, HIV enfeksiyonu, miyokard enfaktüsü, sigara ve alkol kullanımı, ağır el işi gerektiren mesleki yatkınlık, geçirilmiş travma öyküsü gibi bir çok etyolojik faktör tanımlanmıştır ${ }^{3-5}$. Dupuytren hastalığ 1 histopatolojik olarak; proliferatif faz, involusyonel faz ve rezidüel faz olarak Luck tarafından 3 evreye ayrılmıştır ${ }^{6}$. Klinik olarak ise parmaklardaki ekstansiyon kaybı derecesine göre Tubiana tarafindan 4 evreye ayrılmıştır ${ }^{7}$. Cerrahi; MKF eklemde $>30^{\circ}$ fleksiyon kontraktürü, PİP eklemde herhangi bir derecede kontraktür ve ayrıca ağrılı nodül varlığında endikedir ${ }^{8,9}$. Cerrahi tedavi seçenekleri arasında; total fasiektomi, parsiyel fasiektomi, dermofasiektomi, fasyotomi, perkütan iğne fasyotomisi bulunmaktadır. Bunlar arasında en sik kullanılanı parsiyel fasiektomidir ${ }^{10-13}$. Parsiyel fasiektomi McGrouther tarafindan tanımlanmış olup sadece anormal olan palmar ve dijital fasyanın rezeksiyonunu içerir ${ }^{8}$.

Bu makalede dupuytren kontraktürü nedeniyle parsiyel fasiektomi uygulanan 32 hastanın demografik ve klinik özellikleri, fonksiyonel sonuçları, komplikasyon ve nüks oranları güncel literatür eşliğinde tartışılmıştır.

\section{Gereç ve Yöntem}

Çalışmamıza başlamadan önce Bursa Uludağ Üniversitesi Tıp Fakültesi Klinik Araştırmalar Etik Kurulu' ndan onay alındı (Karar no: 2018-21/5). Eylül 2007Ocak 2018 tarihleri arasında dupuytren kontraktürü nedeniyle parsiyel fasiektomi ugulanan 32 hasta retrospektif olarak değerlendirildi. Hastaların yaş, cinsiyet, taraf, dominant el, tutulan parmaklar, kontraktürün başlama yaşı, cerrahi esnasındaki yaş gibi demografik verileri ile meydana gelen komplikasyonlar, nüks ve cerrahi sonrası düzelme miktarı geriye dönük incelendi. Aile öyküsü, sigara ve alkol kullanımı, diyabet, karaciğer hastalığı, epilepsi, ağır el işi gerektiren mesleki yatkınlık, geçirilmiş travma öyküsü gibi dupuytren hastalığının etiyolojisinde rol oynayan faktörler sorgulandı. Ameliyat öncesi tüm hastaların en fazla kontraktür bulunan parmağında, MKF ve PİP eklem ekstansiyon kaybı gonyometre ile ölçülerek total pasif ekstansiyon kaybı (TPEK) hesaplandı. Hastalar ölçülen TPEK'na göre Tubiana tarafindan tanımlanan 4 evreye ayrildı. MKF eklemde $>30^{\circ}$ ve/veya PIP eklemde herhangi bir derecede kontraktür varlığı ya da 'table top testi' pozitifliği cerrahi endikasyon kriteri olarak belirlendi. Daha önce ameliyat edilmiş ve nüks gelişen hastalar çalışmaya dahil edilmedi. Rejyonel ya da genel anestezi uygulanan hastaların cerrahi işlemi (parsiyel fasiektomi), kola uygulanan turnike altında 4.3 kat büyütmeli cerrahi loop kullanılarak yapıldı. Ameliyat sonrası tüm hastalara 2 hafta süreyle MKF ve interfalangeal eklemleri ekstansiyonda tutan volar alçı-atel uyguland. Ameliyattan 7 gün sonra tüm hastalara MKF ve PIP eklem hareket açıklığını sağlamak için aktif ve pasif, fleksiyon/ekstansiyon egzersizleri başlandı. İkinci haftanın sonunda dikişler alınarak atel çıkarıldı (Şekil 1). Sekizinci haftanın sonuna kadar parmakları ekstansiyonda tutan volar gece splinti uyguland1. Ameliyat sonrasi son kontrollerde hastaların MKF ve PİP eklem ekstansiyon kaybı gonyometre ile ölçülerek TPEK hesapland1.

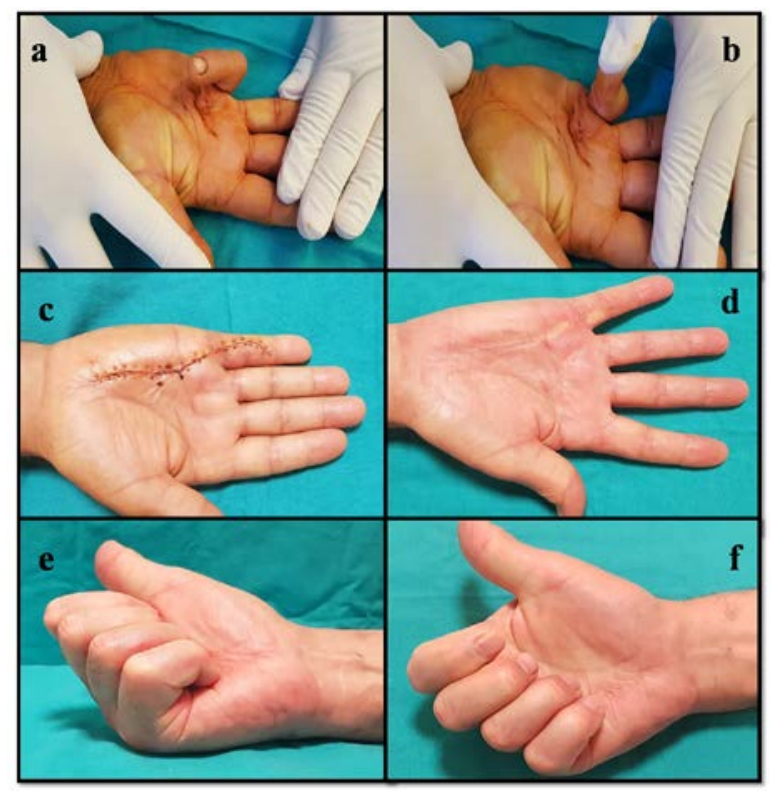

Sekil 1:

Ameliyat öncesi klinik görünüm (a), pasif ekstansiyonda 5. parmağın klinik görünümü (b), parsiyel fasiektomiden 14 gün sonra dikişler alındığında klinik görünüm (c), İkinci ayın sonunda parmakların fonksiyonel görünümü $(d, e, f)$.

Veriler, Microsoft Excel programina girilerek ortalama ve standart hata değerleri hesaplandı ve elde edilen sonuçlar literatür eşliğinde tartışıldı.

\section{Bulgular}

Parsiyel fasiektomi uygulanan 32 hastanın 28'i erkek, 4'ü kadın, erkek/kadın oranı: 7/1 idi. Hastalığın başlangıcındaki ortalama yaş $55.4 \pm 7.1$, cerrahi esnasın- 


\section{Dupuytren Kontraktürü}

daki ortalama yaş $60.4 \pm 8.1$ olarak tespit edildi. 20 hastada dominant el tutulumu olup, 15 hastada sağ el, 17 hastada sol el tutulumu vardı (Tablo I). 7 hastada (\%21.875) aile öyküsü, 22 hastada sigara kullanımı (\%68.75), 6 hastada (\%18.75) düzenli alkol kullanımı, 10 hastada (\%31,25) tip 2 diyabet, 2 hastada (\%6.25) karaciğer hastalığı, 1 hastada (\%3.125) epilepsiye bağlı uzun süre barbitürat kullanımı gibi etiyolojik faktörler mevcuttu. 6 hastada (\%18.75) ise herhangi bir etiyolojik faktör tespit edilmedi (Tablo II). Hastaların sistemik muayenesinde Peyronie hastalığı, Ledderhose hastalığı gibi dupuytren hastalığı ile birlikte görülen hastalıklara rastlanmadı. 4 hastada (\%12.5) bilateral tutulum olup, diğer taraf cerrahi endikasyon kriterleri dışında olduğundan ameliyat edilmedi. 16 hastada (\%50) tek parmak, 11 hastada (\%34.375) iki parmak, 5 hastada (\%15.625) üç parmak tutulumu vard1. En s1k etkilenen parmak 26 hasta (\%81.25) ile yüzük parmağı olup, 18 hastada (\%56.25) küçük parmak, 8 hastada (\%25) orta parmak, 1 hastada (\%3.125) işaret parmağı tutulumu vard1.

Tablo I. Hastaların demografik ve klinik özellikleri.

\begin{tabular}{|ll|}
\hline Hasta sayısı & 32 \\
\hline $\begin{array}{l}\text { Cinsiyet } \\
\text { Hastalığın başlangıcın- }\end{array}$ & Erkek: 28 (\%87.5), kadın: 4 (\%12.5) \\
daki ortalama yaş & $55.4 \pm 7.1$ (dağılım: $43-70$ yıl) \\
$\begin{array}{l}\text { Cerrahi sırasındaki } \\
\text { ortalama yaş }\end{array}$ & $60.4 \pm 8.1$ (dağılım: $47-73$ yıl) \\
$\begin{array}{l}\text { Taraf } \\
\text { Dominant el }\end{array}$ & Sağ: 15(\%46.875), sol: 17 (\%53.125) \\
$\begin{array}{l}\text { Komplikasyon } \\
\text { Nüks }\end{array}$ & $3(\% 62,5)$ \\
$\begin{array}{l}\text { Ortalama takip süresi } \\
\text { (ay) }\end{array}$ & $1(\% 3.125)$ \\
\hline
\end{tabular}

Tablo II. Etyolojik faktörler.

\begin{tabular}{|ll|}
\hline Etyolojik faktörler & Hasta sayısı (\%) \\
\hline Aile öyküsü & $7(\% 21.875)$ \\
Sigara kullanımı & $22(\% 68.75)$ \\
Alkol kullanımı & $6(\% 18.75)$ \\
Tip 2 diyabet & $10(\% 31,25)$ \\
Karaciğer hastalığı & $2(\% 6.25)$ \\
Epilepsi & $1(\% 3.125)$ \\
Titreşim maruziyeti (işçi) & $12(\% 37.5)$ \\
Travma öyküsü & $1(\% 3.125)$ \\
\hline
\end{tabular}

Ameliyat öncesi ölçülen TPEK'na göre hastalar, Tubiana tarafından tanımlanan 4 evreye ayrıldı. 5 hasta (\%15.625) evre I, 9 hasta (\%28.125) evre II, 13 hasta (\%40.625) evre III, 5 hasta (\%15.625) evre IV olarak sınıflandırıldı (Tablo III). Ameliyat öncesi MKF eklem ortalama pasif ekstansiyon kayb1 $55.15^{\circ} \pm 15.88$, PİP eklem ortalama pasif ekstansiyon kaybi $35^{\circ} \pm 21.77$, ortalama TPEK $89.68^{\circ} \pm 30.29$ olarak bulundu. Ameliyat sonrası son kontrollerde ölçülen MKF eklem ortalama pasif ekstansiyon kayb1 $1.56^{\circ} \pm 2.97$, PİP eklem ortalama pasif ekstansiyon kayb $1.53^{\circ} \pm 4.28$, ortalama TPEK $6.09^{\circ} \pm 6.44$ olarak bulundu (Tablo IV). Elde edilen ekstansiyon kazancı MKF eklemde \%97.17, PIP eklemde \%87.05, total ekstansiyon kazanc1 \%93.2 olarak bulundu.

Tablo III. Tubiana sınıflamasına göre hastaların dağ1limi.

\begin{tabular}{|ccc|}
\hline Evre & Total pasif ekstansiyon kaybı & Hasta sayısı (\%) \\
\hline I & $\left(0^{\circ}-45^{\circ}\right)$ & $5(\% 15.625)$ \\
II & $\left(45^{\circ}-90^{\circ}\right)$ & $9(\% 28.125)$ \\
III & $\left(90^{\circ}-135^{\circ}\right)$ & $13(\% 40.625)$ \\
IV & $\left(>135^{\circ}\right)$ & $5(\% 15.625)$ \\
\hline
\end{tabular}

Tablo IV. Pre-operatif ve post-operatif son kontrollerde ölçülen pasif ekstansiyon kaybı.

\begin{tabular}{|ccc|}
\hline Eklem & Pre-operatif & Post-operatif \\
\hline MKF & $55.15^{\circ} \pm 15.88$ & $1.56^{\circ} \pm 2.97$ \\
PiP & $35^{\circ} \pm 21.77$ & $4.53^{\circ} \pm 4.28$ \\
Total & $89.68^{\circ} \pm 30.29$ & $6.09^{\circ} \pm 6.44$ \\
\hline
\end{tabular}

Ortalama takip süresi $70 \pm 44$ ay olup, bu süre içerisinde 1 hastada (\%3.125) nüks görüldü. 2 hastada pansumanlara sekonder iyileşen cilt nekrozu, 1 hastada geçici hipoestezi olmak üzere toplam 3 hastada (\%9.375) komplikasyon meydana geldi.

\section{Tartışma ve Sonuç}

Çalışma ve günlük aktivitelerde işlev bozukluğuna yol açan dupuytren hastalığının tedavisi genellikle cerrahidir. Özellikle PİP eklem kontraktür süresi arttıkça ligamentlerin pozisyonundaki kalıcı değişikliğe bağlı olarak eklem kontraktürü geri dönüşümsüz hale gelir. Kontraktürün düzeltilebilmesi için cerrahinin zamanlaması önemlidir. Bu nedenle, MKF eklemde $>30^{\circ}$ fleksiyon kontraktürü, PİP eklemde herhangi bir derecede kontraktür varlığında cerrahi tedavi önerilmekte$\operatorname{dir}^{9,14}$. Cerrahi tedavinin amacı hastalıklı fasyayı çıkarmak ve böylece kontraktürü düzeltmektir. Cerrahi seçenekler, hastalıklı fasyanın basit olarak yırtıldığı fasyotomi ve hastalıklı fasyanın çıkarıldığı fasiektomi olarak iki gruba ayrilabilir ${ }^{15}$.

18. yüzyılda Henry Cline tarafindan patolojik kordlar kesilerek yapılan fasyotomi ya da aponörotomi dupuytren kontraktürü için tanımlanan ilk tedavi oldu ${ }^{16}$. Açık ya da perkütan olarak yapılabilen fasyotomi, MKF eklemin izole kontraktürleri için önerilmiştir ${ }^{17}$. Perkütan iğne fasyotomisi ile kısa vadede mükemmel sonuçlar bildirilmiş olmasına rağmen erken dönemde nüks oranları yüksektir. Özellikle basit tedavi isteyen uzun dönem mükemmel sonuçların daha az önemli 
olduğu yaşlı hastalarda, MKF eklemin izole ve 1lımlı kontraktürlerinde perkütan iğne fasyotomisi önerilmektedir $^{15,18}$.

19. yüzyılın sonunda anestezideki gelişmeler ile birlikte hastalıklı fasyanın tam ya da kısmi eksizyonu dupuytren kontraktürünün standart tedavisi haline geldi. Daha sonra daha az invaziv ve komplikasyon oranının düşük olması nedeniyle yalnızca hastalıklı fasyanın çıkarıldığ 1 parsiyel fasyektomi en sık kullanılan yöntem oldu ${ }^{16,19,20}$.

Sistematik bir derlemede parsiyel fasiektomi uygulanan hastaların \%61-97'sinde \%100’lük bir düzelme olduğu ve kontraktür açılarında \%58-79 derecelik bir iyileşme olduğu bildirilmiştir ${ }^{10}$. Coert ve ark. parsiyel fasiektomi uyguladıkları 261 hastadan oluşan çalışmalarında; MKF eklemde \%94.2'lik ekstansiyon kazancı, PIP eklemde \%71.5'lik ekstansiyon kazancı bildirmişlerdir $^{19}$. Parsiyel fasiektomi uyguladığımız 32 hastada tatmin edici sonuçlar elde edildi. Hastaların son yapılan kontrollerinde total ekstansiyon kazancı \%93.2 olarak bulundu.

Crean ve ark. parsiyel fasiektomi uygulanan hastalarda komplikasyon oranını ortalama \%24 (\%18-37) olarak bildirmiştir. En sık görülen komplikasyon \%18 ile nöropraksi olup, dijital sinir yaralanmas1 $\% 4.3$, dijital arter yaralanması \%1, enfeksiyon \%3.6, hematom \%1.1, kompleks bölgesel ağrı sendromu \%5.5, cilt problemleri \%2.4 olarak bildirilmiştir ${ }^{10}$. Çalışmamızda 2 hastada pansumanlara sekonder iyileşen cilt nekrozu, 1 hastada geçici hipoestezi olmak üzere toplam 3 hastada (\%9.375) komplikasyon meydana geldi. Dias ve Braybrooke dupuytren kontraktürü nedeniyle ameliyat olan 1117 hastanın ameliyat sonuçlarını gözden geçirdikleri çalışmalarında cerrahi öncesi deformitenin şiddeti ile komplikasyon oranları arasında açık bir korelasyon tespit etmişler. Buna göre deformitenin şiddeti arttıkça meydana gelebilecek komplikasyon oranlarının artacağı kanısına varmışlar ${ }^{21}$.

Nüks oranları tedavi şekline ve hastalara ilişkin faktörlere bağlı olmakla birlikte aynı zamanda takip süresine ve nüksün tanımına bağlıdır ${ }^{10}$. Literatürde nüks için çeşitli tanımlamalar yapılmıştır. Son zamanlarda yapılan bir çalışmada nüks, cerrahi sırasında tam veya tama yakın düzelme sağlanan eklem kontraktürünün yeniden şekillenmesi olarak tanımlanmıştır ${ }^{21}$. Yazarlar 7 yıllık takip süresince nüks oranını bu tanıma göre $\% 12$ olarak bildirilmiştir ${ }^{22}$. Ancak farklı nüks tanımları ile literatürde değişik oranlarda nüks bildirilmiştir. Tonkin ve ark. nüks oranlarını kadınlarda \%54, erkeklerde $\% 25$ olarak bildirmiştir ${ }^{23}$. Mäkelä ve ark. ortalama 3.2 yıllık takip süresince nüks oranını \%27 olarak bildirmiştir ${ }^{24}$. Anwar ve ark. 109 kadın hastadan oluşan çalışmalarında nüks oranını \%14 olarak bildirmiștir ${ }^{25}$. Sistematik bir derlemede ortalama 4 yıllık takip süresince nüks oranı $\% 39$ olarak bildirilmiştir $^{10}$. Son zamanlarda yapılan bir çalışmada nüks oranlarını azaltmak için parsiyel fasiektomi uygulanan hastalara 24 hafta gece splinti ve en az 8 hafta ev egzersizi protokolü uygulanmış. 30 hasta ortalama 4.9 yıl takip edildiğinde 2 ay içerisinde splint kullanımını bırakmış 2 hastada (\%7) nüks gelişmiş ${ }^{26}$. Parsiyel fasiektomi uyguladığımız 32 hastaya ameliyat sonrası 8 hafta gece splinti uygulandı ve yalnızca 1 hastada (\%3.125) nüks görüldü. Nüks gelişen hasta aile öyküsü pozitif ve Tubiana sınıflamasına göre evre IV (ameliyat öncesi TPEK:145')'tü.

Dupuytren kontraktürünün cerrahi tedavisinde; iğne veya açık fasyotomi, segmental veya parsiyel fasiektomi ve dermofasiektomi gibi teknikler kullanılmakta$\mathrm{d}^{2}{ }^{27}$. Bu ameliyat teknikleri ile ilgili başarılı sonuçlar bildiren çalışmalar bulunmasına rağmen, farklı ameliyat tekniklerinin karşılaştırılıdığı randomize kontrollü çalışmalar yeterli sayıda değildir ${ }^{13}$. Van Rijssen ve ark. yapmış oldukları prospektif bir çalışmada; hasta memnuniyeti ve parmak ekstansiyonu açısından parsiyel fasiektominin, perkütan iğne fasyotomisine göre daha iyi sonuçlara sahip olduğunu bulmuşlardır ${ }^{28}$. Ayrıca sistematik bir derlemede nüks oranı; iğne fasyotomisinde (\%50-58), parsiyel fasiektomiden (\%1239) anlamlı derecede daha yüksek bulunmuştur ${ }^{29}$. Bryan ve Ghorbal, küçük bir cilt insizyonu kullanarak yaptıkları kapalı fasyotomi ile ortalama 5.3 y1llı takip sonrası nüks oranını $\% 45$ olarak bildirmişlerdir ${ }^{30}$. Moermans tarafindan tanımlanan, küçük kavisli cilt insizyonları kullanılarak yapılan segmental fasiektomi ile ortalama 2.9 y1llık takip sonrası \%38 nüks bildirilmiştir ${ }^{31}$. Aynı tekniğin kullanıldığı bir başka çalışmada, ortalama 2.5 yıllık takip sonrası nüks oranı $\% 16$ olarak bildirilmiştir ${ }^{32}$. Dermofasiektomide, parsiyel fasyektomiden farklı olarak hastalıklı ciltde eksize edilir ve yara yeri tam kat cilt grefti ile kapatılır. Yaygin cilt tutulumu olan diffüz tip dupuytren kontraktürünün cerrahi tedavisinde önerilmektedir. Diffüz tutulumu olan 103 hastalık bir seride nüks oranı \%11.6 olarak bulunmuştur ${ }^{33}$. Ancak herhangi bir cerrahi tekniği önermek için; fonksiyonel sonuçlar, komplikasyonlar ve nüks oranlarını da içeren prospektif randomize kontrollü çalışmalara ihtiyaç vardır.

Parmakların aktif ve pasif, fleksiyon/ekstansiyon egzersizlerine hastanın ağrısı izin verdiği ölçüde; eklem sertliğini önlemek, elde edilen yeni hareket açıklığını korumak ve deformitenin nüks etmesini önlemek için mümkün olan en kısa sürede başlanmalıdır ${ }^{14,35}$. Çalışmamızda ameliyattan 7 gün sonra tüm hastalara MKF ve PİP eklem hareket açıklığını sağlamak için aktif ve pasif, fleksiyon/ekstansiyon egzersizleri başlandı ve 8 hafta ev egzersizi protokolü uyguland1. Ameliyat sonrası uygulanan volar alç1-atel ikinci haftanın sonunda çıkarılarak sekizinci haftanın sonuna kadar parmakları ekstansiyonda tutan volar gece splinti uygulandi.

Dupuytren hastalığında; pozitif aile öyküsü, bilateral tutulum, ektopik hastalık varlığı (Garrod'un eklem yastıkçıkları, Ledderhose hastalığı, Peyronie hastalığı) 


\section{Dupuytren Kontraktürü}

ve başlangıç yaşının 45'in altında olması kötü prognositik faktörler olarak tanımlanmıştır. Kötü prognositik faktörlere sahip hastalarda hastalık daha agresif seyreder ve nüks oranları daha yüksektir ${ }^{3,27}$. Çalışmamızda 7 hastada (\%21.875) aile öyküsü pozitif, 4 hastada (\%12.5) bilateral tutulum olup, ektopik hastalığa rastlanmadi.

Dupuytren hastalığının patolojik anatomisi ile etiyolojik ve prognositik faktörleri literatürde ayrıntılı bir şekilde tanımlanmasına rağmen altın standart bir tedavi yöntemi konusunda görüş birliği yoktur. Tedavinin başarısı için eklem kontraktürleri geri dönüşümsüz hale gelmeden cerrahi planlanması önemli olup, cerrahi prosedürler loop altında geniş bir cerrahi sahada komşu nörovasküler yapılara ve fleksör tendonlara zarar vermeyecek şekilde gerçekleştirilmelidir. Cerrahi sonrası nüksü önlemek ve parmakların hareket açıklığını tekrar kazanmak için erken aktif/pasif hareket başlanmalı ve gece splinti kullanılmalıdır.

Sonuç olarak; MKF ve PIPP eklem kontraktüründe yeterli düzelme sağlaması, komplikasyon ve nüks oranlarının düşük olması nedeniyle parsiyel fasiektomi dupuytren kontraktürünün cerrahi tedavisinde etkili ve güvenilir bir yöntemdir.

\section{Kaynaklar}

1. Thurston A. Dupuytren's disease or Cooper's contracture? Kenneth Fitzpatrick Russell Memorial Lecture. ANZ J Surg 2003;73(7):529-35.

2. Townley WA, Baker R, Sheppard N, Grobbelaar AO Dupuytren's contracture unfolded. BMJ 2006;332(7538):397400.

3. Hindocha S. Risk Factors, Disease Associations, and Dupuytren Diathesis. Hand Clin 2018;34(3):307-14

4. Rayan GM. Clinical presentation and types of Dupuytren's disease. Hand Clinic 1999;15(1):87-96.

5. Geoghegan JM, Forbes J, Clark DI, Smith C, Hubbard R. Dupuytren's disease risk factors. J Hand Surg $\mathrm{Br}$ 2004;29(5):423-6.

6. Luck JV. Dupuytren's contracture; a new concept of the pathogenesis correlated with surgical management. J Bone Joint Surg Am 1959:41(4):635-64.

7. Tubiana R. Evaluation of deformities in Dupuytren's disease. Ann Chir Main 1986;5(1):5-11.

8. McGrouther DA. Dupuytren's contracture. In: Green's operative hand surgery. 6th ed. Philadelphia: Elsevier; 2005.159-85.

9. Smith AC. Diagnosis and indications for surgical treatment. Hand Clin. 1991;7(4):635-42.

10. Crean SM, Gerber RA, Graverand MP, Boyd DM, Cappelleri JC. The efficacy and safety of fasciectomy and fasciotomy for Dupuytren's contracture in European patients: a structured review of published studies. J Hand Surg Eur 2011;36(5):396-407.

11. Desai SS, Hentz VR. The treatment of Dupuytren disease. J Hand Surg Am 2011; 36(5):936-42.

12. Eaton C. Percutaneous fasciotomy for Dupuytren's contracture. J Hand Surg Am 2011;36(5):910-5.

13. Becker GW, Davis TR. The outcome of surgical treatments for primary Dupuytren's disease-a systematic review. J Hand Surg Eur 2010;35(8):623-6.
14. Au-Yong IT, Wildin CJ, Dias JJ, Page RE. A review of common practice in Dupuytren surgery. Tech Hand Up Extrem Surg 2005;9(4):178-87.

15. van Rijssen AL, Werker PM. Percutaneous needle fasciotomy in dupuytren's disease. J Hand Surg Br 2006;31(5):498-501.

16. Wilson GR. Current surgical treatment of Dupuytren's disease. Br J Clin Pract 1997;51(2):106-10.

17. Bryan AS, Ghorbal MS. The long-term results of closed palmar fasciotomy in the management of Dupuytren's contracture. J Hand Surg Br 1988;13(3):254-6.

18. Foucher G, Medina J, Navarro R. Percutaneous needle aponeurotomy: complications and results. J Hand Surg $\mathrm{Br}$ 2003;28(5):427-31.

19. Coert JH, Nérin JP, Meek MF. Results of partial fasciectomy for Dupuytren disease in 261 consecutive patients. Ann Plast Surg 2006;57(1):13-7.

20. Werker PM, Pess GM, van Rijssen AL, Denkler K. Correction of contracture and recurrence rates of Dupuytren contracture following invasive treatment: the importance of clear definitions. J Hand Surg Am 2012;37(10):2095-105.

21. Dias JJ, Braybrooke J. Dupuytren's contracture: an audit of the outcomes of surgery. J Hand Surg Br 2006;31(5):514-21.

22. Dias JJ, Singh HP, Ullah A, Bhowal B, Thompson JR. Patterns of recontracture after surgical correction of Dupuytren disease. J Hand Surg Am 2013;38(10):1987-93.

23. Tonkin MA, Burke FD, Varian JPW. Dupuytren's contracture: a comparative study of fasciectomy and dermofasciectomy in one hundred patients. J Hand Surg Br 1984;9(2):156-62.

24. Mäkelä EA, Jaroma H, Harju A, Anttila S, Vainio J. Dupuytren's contracture: the long-term results after day surgery. J Hand Surg Br 1991;16(3):272-4.

25. Anwar MU, Al Ghazal SK, Boome RS. Results of surgical treatment of Dupuytren's disease in women: a review of 109 consecutive patients. J Hand Surg Am 2007;32(9):1423-8.

26. Kitridis D, Karamitsou P, Giannaros I, Papadakis N, Sinopidis C, Givissis P. Dupuytren's disease: limited fasciectomy, night splinting, and hand exercises-long-term results. Eur J Orthop Surg Traumatol 2018;doi:10.1007/s00590-018-2340-6. [Epub ahead of print]

27. Dias JJ, Aziz S. Fasciectomy for Dupuytren Contracture. Hand Clin 2018;34(3):351-66.

28. van Rijssen AL, Gerbrandy FS, Ter Linden H, Klip H, Werker PM. A comparison of the direct outcomes of percutaneous needle fasciotomy and limited fasciectomy for Dupuytren's disease: a 6-week followup study. J Hand Surg Am 2006;31(5):717-25.

29. Chen NC, Srinivasan RC, Shauver MJ, Chung KC. A systematic review of outcomes of fasciotomy, aponeurotomy, and collagenase treatments for Dupuytren's contracture. Hand 2011;6(3):250-5.

30. Bryan AS, Ghorbal MS. The long-term results of closed palmar fasciotomy in the management of Dupuytren's contracture. J Hand Surg Br 1998;13(3):254-6.

31. Moermans JP. Long-term results after segmental aponeurectomy for Dupuytren’s disease. J Hand Surg Br 1996;21(6):797800.

32. Clibbon JJ, Logan AM. Palmar segmental aponeurectomy for Dupuytren's disease with metacarpophalangeal fexion contracture. J Hand Surg Br 2001;26(4):360-1.

33. Armstrong JR, Hurren JS, Logan AM. Dermofasciectomy in the management of Dupuytren's disease. J Bone Joint Surg Br 2000;82(1):90-4.

34. Abbott K, Denney J, Burke FD, McGrouther DA. A review of attitudes to splintage in Dupuytren's contracture. J Hand Surg Br 1987;12(3):326-8. 
